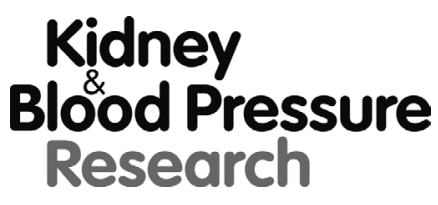

Kidney Blood Press Res 2018;43:234-245

DOI: $10.1159 / 000487677$

Published online: February 27, 2018

Accepted: February 15, 2018

This article is licensed under the Creative Commons Attribution-NonCommercial-NoDerivatives 4.0 International License (CC BY-NC-ND) (http//www.kargercom/Services/OpenAccessLicense). Usage and distribution for commercial purposes as well as any distribution of modified material requires written permission.

\title{
The Relationships of the Fractional Excretion of Uric Acid with Brachial-Ankle Pulse Wave Velocity and Ankle Brachial Index in Chinese Young Adults
}

\author{
Jia-Wen Hu Yang Wang $^{\mathrm{a}, \mathrm{b}} \quad$ Chao Chu ${ }^{\mathrm{a}, \mathrm{b}} \quad$ Yu Yana ${ }^{\mathrm{a}, \mathrm{b}} \quad$ Keke Wanga,b \\ Wenling Zhenga,b Qiong Maa, Yong-bo Lva ${ }^{a, b} \quad$ Yin Deng ${ }^{a} \quad$ Bo Yan ${ }^{a}$ \\ Jian-Jun $\mathrm{Mu}^{\mathrm{a}, \mathrm{b}}$
}

aDepartment of Cardiology, First Affiliated Hospital of Medical School, Xi'an Jiaotong University, Xi'an,

${ }^{b}$ Key Laboratory of Molecular Cardiology of Shaanxi Province, Xi'an, China

\section{Key Words}

$\mathrm{UA} \cdot \mathrm{FEUA} \cdot \mathrm{BaPWV} \cdot \mathrm{ABI}$

\begin{abstract}
Background/Aims: Elevated serum uric acid (UA) was intimately correlated with vascular stiffness and abnormal ankle brachial index (ABI) in various populations. These correlations lost significance after adjustment for estimated glomerular filtration rate (eGFR), indicating that the association of UA and brachial-ankle pulse wave velocity (baPWV) or ABI might be driven by kidney function. UA is predominantly eliminated through the kidneys, and metabolic disorders can influence the clearance of UA. In this study, we aimed to explore the putative correlation between FEUA and baPWV or ABI to determine to what extent the associations with UA were affected by renal function. Methods: This cross-sectional study enrolled 2351 participants, who underwent general health screening in Hanzhong people's hospital from March to June of 2017. BaPWV and ABI were measured using a volume-plethysmographic apparatus (BP-203RPEII; Nihon Colin, Tokyo, Japan). FEUA was divided into quartiles: Q1:FEUA $\leq 3.07$; Q2:3.07<FEUA $\leq 5.32 ;$ Q3: 5.32<FEUA $\leq 9.19$; and Q4: FEUA> 9.19. Results: Lower FEUA predicted a higher prevalence of high baPWV and low ABI ( $p$ for trend $<0.001$ ). The respective ORs for high baPWV from the first to the third quartiles of FEUA were $1.777(1.323,2.387)$; $1.561(1.158,2.104)$; and $1.680(1.250,2.259)$. The prevalence of low ABI was greatly elevated with the decrement of FEUA [ORs for the first to third FEUA quartiles were 6.977(2.062, 23.610); $5.123(1.475,17.790)$; and $2.685(0.709,10.171)$, respectively]. The association of FEUA and ABI was independent of related confounding factors. However, the association between FEUA and baPWV was greatly influenced by corresponding confounders, especially gender. The efficacy of FEUA in the prediction of low ABI was stronger than that of serum UA. However, serum UA

J. Hu and Y. Wang contributed equally to this work.

\begin{tabular}{ll}
\hline Jian-Jun Mu, MD, PhD & Department of Cardiology, First Affiliated Hospital of Medical School, Xian Jiaotong University \\
& No.277, Yanta West Road, Xi'an ,710061 (China) \\
Tel. +86-29-85323804, E-Mail mujjun@163.com
\end{tabular}
\end{abstract}




\section{Kidney \\ Blood Pressure Research}

Kidney Blood Press Res 2018;43:234-245

\begin{tabular}{l|l}
\hline DOI: 10.1159/000487677 & (C) 2018 The Author(s). Published by S. Karger AG, Base
\end{tabular}

Published online: February 27, 2018 www.karger.com/kbr

Hu et al.: Correlations of FEUA with BaPWV and ABI

was more powerful in the prediction of high baPWV. Conclusion: Kidney function exerted a profound influence on the relationship between UA and baPWV or ABI, revealing complex interactions among cardiovascular risk factors.

\section{Introduction}

Uric acid (UA), the final oxidative metabolite of purine nucleotide in humans, has been identified as a prominent risk factor for atherosclerotic diseases [1]. Compelling evidence has addressed the concept that increased UA intimately correlated with cardiovascular risk factors, such as metabolic syndrome (MetS), dyslipidaemia, obesity, and hypertension [1-3]. The interactions of these factors synergistically contributed to the pathogenesis and progression of cardiovascular disease (CVD). Several clinical and animal studies have identified that lowing UA levels prevented or reversed the progression of the MetS and hypertension $[4,5]$.

The brachial-ankle pulse wave velocity (baPWV) for large and media arterial elasticity and ankle brachial index (ABI) for systemic atherosclerosis status are two easy-access and effective indices reflecting overall vascular status. Increased baPWV and lowered ABI are associated with higher morbidity and mortality of CVD in high risk or even general populations [6-8]. All-cause and CVD mortality were 16.983-fold and 18.441-fold higher in patients with $\mathrm{ABI} \leq 0.4$ and $\mathrm{UA}>536 \mu \mathrm{mol} / \mathrm{L}$, respectively, than in those with $0.9<\mathrm{ABI} \leq 1.4$ and $\mathrm{UA} \leq 357 \mu \mathrm{mol} / \mathrm{L}$ [9]. A Japanese study in the general population suggested that every $20 \%$ increment in baPWV predicted a 1.30 -fold greater cardiovascular risk after adjusting for confounders [10].

Clinical observational studies have proved that increased serum UA levels were intimately correlated with vascular stiffness and abnormal $A B I$ in various populations independent of other cardiovascular risk factors [11-13]. However, these associations lost significance after adjustment for eGFR, indicating that the association of UA and baPWV or ABI might be driven by kidney function [12]. UA is mainly eliminated by the kidney, which diminishes in obese, hypertensive and MetS subjects [5]. It has been found in gout patients that metabolic disorders influendced the clearance of uric acid [14]. Thus, the decreased excretion of UA might modify the relationship between UA and metabolic parameters. Nevertheless, few studies have paid attention to this.

In this study, we aimed to explore whether the putative association still holds in UA and baPWV or ABI after taking kidney function into consideration by using fractional excretion of uric acid(FEUA), a good indicator of the balance of UA, and determine to what extent the associations were affected by renal function.

\section{Materials and Methods}

\section{Participants}

A total of 2351 participants, who underwent general health screening in Hanzhong people's hospital and were available for the results of UA, baPWV, and ABI, were recruited from March to June of 2017. The exclusion criteria were as follows: secondary hypertension; history of infectious diseases or abnormal liver function; eGFR < $60 \mathrm{~mL} / \mathrm{min} / 1.73 \mathrm{~m} 2 ; \mathrm{ABI}>1.4$; pregnancy; and alcohol abuse. All procedures complied with the Declaration of Helsinki and the research protocol was approved by the Ethics Committee of the First Affiliated Hospital of Medical School, Xi'an Jiaotong University(code: 2015-128). Upon admission, written informed consent was obtained from each participant.

Demographic and anthropometric data

Basic demographic information (including age, sex, history of diseases, smoking habits and alcoholic 


\section{Kidney Blood Pressure Research}

Table 1. CKD-EPI equation for non-blacks. Abbreviations: Scr =serum creatinine; eGFR =estimated glomerular filtration rate

\begin{tabular}{lcc}
\hline Gender & Scr $($ umol/L $)$ & Equation \\
\hline \multirow{2}{*}{ Female } & $\leq 62$ & eGFR $=144 \times(\mathrm{Scr} / 0.7)^{-0.329 \times(0.993)^{\text {age }}}$ \\
& $>62$ & eGFR $=144 \times(\mathrm{Scr} / 0.7)^{-1.209 \times(0.993)^{\text {age }}}$ \\
Male & $\leq 80$ & eGFR $=144 \times(\mathrm{Scr} / 0.9)^{-0.411 \times(0.993)^{\text {age }}}$ \\
& $>80$ & eGFR $=144 \times(\mathrm{Scr} / 0.9)^{-1.209 \times(0.993)^{\text {age }}}$ \\
\hline
\end{tabular}

consumption) was obtained by trained staff using a standard questionnaire. Participants took off their shoes and wore light clothes for anthropometric parameter measurements. Body mass index (BMI) was calculated using weight in kilograms (kg) divided by the square of height in metres (m2). Blood pressure (BP) was measured by certified physicians using electric sphygmomanometers. Participants were instructed to sit in a resting position for more than $5 \mathrm{~min}$ and refrain from exercise, smoking, alcohol, coffee, or tea prior to BP measurement. BP was measured three times at 1-min intervals. Hypertension was defined as a mean systolic blood pressure (SBP) of $\geq 140 \mathrm{mmHg}$, and/or mean diastolic blood pressure (DBP) of $\geq 90 \mathrm{mmHg}$, and/or a history of hypertension with current use of antihypertensive medications.

\section{Laboratory analyses}

Blood samples were obtained after an overnight fast and were centrifuged at $2500 \mathrm{~g}$ for $15 \mathrm{~min}$ within $2 \mathrm{~h}$. Morning urine samples were collected after blood drawing. Samples were packaged in aliquots for further analysis. Basic biochemistry parameters (including lipid profiles, fasting serum glucose, serum creatinine, serum uric acid, urinary creatinine and urinary uric acid) were analysed using a Hitachi 7600110 Chemistry Autoanalyzer (Hitachi, Ltd., Tokyo, Japan). FEUA was calculated as the ratio of urinary uric acid in umol/L to serum uric acid in umol/L divided by the ratio of urinary creatinine in umol/L to serum creatinine in umol/L [15]. Estimated glomerular filtration rate (eGFR) was calculated using the Chronic Kidney Disease Epidemiology Collaboration equation as shown in Table 1.

\section{Measurement of BaPWV and ABI}

BaPWV and ABI were measured using a volume-plethysmographic apparatus (BP-203RPEII; Nihon Colin, Tokyo, Japan)[16, 17]. Participants were in the supine position with cuffs, which were connected to a plethysmographic sensor and an oscillometric pressure sensor, wrapped around both the brachium and ankles. BaPWV was calculated according to the following equation adjusted for age, weight, and height. Averages of baPWVs from both sides were used for analysis:

$$
\mathrm{BaPWV}=\frac{\mathrm{La}-\mathrm{Lb}}{\Delta \mathrm{Tba}} \mathrm{cm} / \mathrm{s}
$$

La: the path lengths from the suprasternal notch to the ankle,

$\mathrm{Lb}$ : the path lengths from the suprasternal notch to the brachium,

$\Delta T$ Tba: the time interval between the wavefront of the brachial waveform and that of the ankle waveform.

The ABIs of both sides were calculated by the highest pressure of the ankle on the corresponding side divided by the highest brachial pressure on either side. The lower ABI of both sides was used for analysis.

\section{Definition of MetS}

Subjects with three or more of the following five conditions were defined as having MetS[18]: Abdominal obesity: waist circumference $\geq 88 \mathrm{~cm}$ for females and $\geq 102 \mathrm{~cm}$ for males; high blood pressure: $\mathrm{SBP} \geq 130 \mathrm{mmHg}$ or DBP $\geq 85 \mathrm{mmHg}$, or taking antihypertensive drug; hypertriglyceridaemia: (TC) $\geq 150 \mathrm{mg}$ / $\mathrm{dL}$ or treatment of dyslipidaemia; high-density lipoprotein cholesterol (HDL-C) $<40 \mathrm{mg} / \mathrm{dL}$ in males or $<50$ $\mathrm{mg} / \mathrm{dL}$ in females; fasting plasma glucose $\geq 100 \mathrm{mg} / \mathrm{dL}$ or treatment for diabetes mellitus(DM).

\section{Statistical analysis}

IBM SPSS Statistics 22.0 (IBM Corp., Chicago, IL, USA) was used for all statistical analyses. Demographic and clinical features of participants were compared across quartiles of FEUA subgroups. Categorical variables were expressed as percentages. Continuous variables were presented as means \pm standard 


\section{Kidney Blood Pressure Research}

Table 2. Demographic and clinical characteristics of participants by quartiles of FEUA. * compared with $\mathrm{Q} 1 ;$ † compared with Q2; $\ddagger$ compared with Q3; Abbreviations: FEUA= fractional excretion of uric acid; $\mathrm{Q}=$ quartile; $\mathrm{DM}=$ diabetes mellitus; $\mathrm{SBP}=$ systolic blood pressure; $\mathrm{DBP}=$ diastolic blood pressure; $\mathrm{TC}=$ total cholesterol; TG=triglycerides; LDL-C=low-density lipoprotein triglycerides cholesterol; HDL-C= Highdensity lipoprotein triglycerides cholesterol; CREs=serum creatinine; UAs=serum uric acid; CREu=urinary creatitine; $\mathrm{UAu}=$ urinary uric acid; eGFR=estimated glomerular filtration rate; baPWV=brachial-ankle pulse wave velocity; $\mathrm{ABI}=$ ankle brachial index

\begin{tabular}{|c|c|c|c|c|c|}
\hline \multirow{2}{*}{ Variables } & \multicolumn{4}{|c|}{ FEUA } & \multirow{2}{*}{$\mathrm{p}$ for trend } \\
\hline & Q1 $\quad(n=588)$ & $\mathrm{Q} 2(\mathrm{n}=587)$ & Q3 $(n=589)$ & $Q 4(n=587)$ & \\
\hline Age(years) & $43 \pm 3$ & $43 \pm 3$ & $43 \pm 3$ & $42 \pm 3$ & 0.211 \\
\hline Sex(male,\%) & 69.6 & $60.8 *$ & $55.3 *$ & $35.9 * \dagger \neq$ & $<0.001$ \\
\hline Smokers(\%) & 56.3 & $47.3 *$ & $42.1 *$ & $26.7 * \dagger \neq$ & $<0.001$ \\
\hline Alcohol drinkers(\%) & 36.7 & 33.1 & $28 *$ & $19.4 * \dagger \neq$ & $<0.001$ \\
\hline Hypertension(\%) & 12.4 & 11.4 & 11.2 & 8.4 & 0.030 \\
\hline $\mathrm{DM}(\%)$ & 2.6 & 2.6 & 3.0 & 2.9 & 0.613 \\
\hline $\mathrm{SBP}(\mathrm{mmHg})$ & $125 \pm 20$ & $123 \pm 16 *$ & $124 \pm 17$ & $121 \pm 16 *$ & 0.002 \\
\hline $\mathrm{DBP}(\mathrm{mmHg})$ & $79 \pm 12$ & $77 \pm 11$ & $77 \pm 12 *$ & $76 \pm 13 *$ & $<0.001$ \\
\hline $\mathrm{BMI}(\mathrm{kg} / \mathrm{m} 2)$ & $24.5 \pm 3.3$ & $24.1 \pm 3.1$ & $24.0 \pm 3.2 *$ & $23.7 \pm 3.1 *$ & $<0.001$ \\
\hline \multicolumn{6}{|l|}{ Laboratory parameters } \\
\hline Glucose (mmol/L) & $4.69 \pm 0.91$ & $4.80 \pm 1.24$ & $4.78 \pm 1.22$ & $4.8 \pm 1.43$ & 0.150 \\
\hline $\mathrm{TC}(\mathrm{mmol} / \mathrm{L})$ & $4.65 \pm 0.80$ & $4.58 \pm 0.85$ & $4.54 \pm 0.81$ & $4.50 \pm 0.75 *$ & 0.001 \\
\hline $\mathrm{TG}(\mathrm{mmol} / \mathrm{L})$ & $1.73 \pm 1.08$ & $1.70 \pm 1.37$ & $1.70 \pm 1.42$ & $1.45 \pm 1.21 * \dagger \neq$ & $<0.001$ \\
\hline LDL-C(mmol/L) & $2.63 \pm 0.80$ & $2.54 \pm 0.68$ & $2.50 \pm 0.65 *$ & $2.48 \pm 0.60 *$ & $<0.001$ \\
\hline HDL-C(mmol/L) & $1.15 \pm 0.26$ & $1.17 \pm 0.27$ & $1.16 \pm 0.26$ & $1.23 \pm 0.27 *$ & $<0.001$ \\
\hline TG/HDL-C & $1.33[0.78-2.14]$ & $1.23[0.79-1.95]$ & $1.17[0.76-1.84]$ & $0.98[0.66-1.52]^{*} \dagger \neq$ & 0.004 \\
\hline CREs(umol/L) & $79.2 \pm 14.6$ & $77.3 \pm 13.2$ & $76.5 \pm 13.8 *$ & $73.2 \pm 13.3 * \dagger$ & $<0.001$ \\
\hline UAs(umol/L) & $320.9 \pm 81.8$ & $294.7 \pm 70.6 *$ & $279.7 \pm 71.0 * \dagger$ & $245.0 \pm 64.1 * \dagger \neq$ & $<0.001$ \\
\hline CREu(umol/L) & $14947 \pm 6413$ & $10221 \pm 5496 *$ & $7203 \pm 4603 * \dagger$ & $4135 \pm 3257 * \dagger \neq$ & $<0.001$ \\
\hline $\mathrm{UAu}(\mathrm{umol} / \mathrm{L})$ & $1042[811-1312]$ & $1321[991-1921]$ * & $1463[972-2272] *$ & $1643[1031-2424 * \dagger$ & $<0.001$ \\
\hline $\mathrm{eGFR}(\mathrm{ml} / \mathrm{min} / 1.73 \mathrm{~m} 2)$ & $96.74 \pm 13.95$ & $96.76 \pm 12.28$ & $96.62 \pm 12.42$ & $96.58 \pm 13.10$ & 0.803 \\
\hline $\mathrm{baPWV}(\mathrm{cm} / \mathrm{s})$ & $1263 \pm 229$ & $1250 \pm 232$ & $1255 \pm 246$ & $1204 \pm 224 * \dagger \neq$ & $<0.001$ \\
\hline $\mathrm{ABI}$ & $1.07 \pm 0.08$ & $1.08 \pm 0.08$ & $1.09 \pm 0.07 *$ & $1.13 \pm 0.07 * \dagger \neq$ & $<0.001$ \\
\hline
\end{tabular}

deviation or medians (inter-quartile range) as appropriate. The Chi-squared test for categorical variables and analysis of variance for continuous variables were used to analyse the differences across FEUA groups followed by post-hoc analysis. Partial correlation and multivariate logistic regression analysis were used to explore the association between FEUA and baPWV or ABI. During logistic regression analysis, baPWV and $\mathrm{ABI}$ were transformed to dichotomous variables: baPWV $<1400 \mathrm{~cm} / \mathrm{s}$ or baPWV $\geqslant 1400 \mathrm{~cm} / \mathrm{s} ; \mathrm{ABI} \leqslant 0.9$ or $\mathrm{ABI}>0.9$. FEUA was log-transformed to achieve normality during analysis. Two-tailed $\mathrm{p}<0.05$ was considered significant.

\section{Results}

\section{Characteristics of the subjects}

Participants were divided into four groups according to quartiles of FEUA: Q1:FEUA $\leq 3.07$; Q2:3.07<FEUA $\leq 5.32 ; \mathrm{Q} 3: 5.32<$ FEUA $\leq 9.19$; and Q4: FEUA> 9.19. The basic characteristics of participants across quartiles of FEUA are summarized in Table 2. Participants in the lowest quartile of FEUA tended to be male, a smoker and an alcoholic drinker and their BP, BMI, total cholesterol (TC), TG, and low-density lipoprotein-cholesterol (LDL-C) were significantly higher than those in the highest quartile of FEUA(all $\mathrm{p}<0.05$ ). HDL-C of group Q1was lower than that of group Q4 ( $\mathrm{p}<0.05)$. Age, history of hypertension or DM, fasting glucose and eGFR showed no significant inter-group differences. Sex-specific analysis showed that baPWV and serum UA were higher in men, while ABI and FEUA were higher in women (Fig. 1).

\section{Correlations between FEUA and baPWV or ABI}

Compared with subjects in the highest quartile of FEUA, baPWV increased (Q1 vs Q4: $1263 \pm 228$ vs $1204 \pm 224 \mathrm{~cm} / \mathrm{s}$ ) and ABI decreased(Q1 vs Q4: $1.07 \pm 0.08$ vs $1.13 \pm 0.07$ ) in those of the lowest FEUA group (Table 2). Correlation analysis showed a significantly positive relationship between $\mathrm{ABI}$ and $\log$-FEUA $(\mathrm{r}=0.229, \mathrm{p}<0.001)$ and a negative relationship 


\section{Kidney Blood Pressure Research}

between baPWV and log-FEUA ( $\mathrm{r}=-0.100, \mathrm{p}<0.001)$. However, these two correlations lost significance after adjusting for age, sex, BMI, smoking habits, alcohol consumption, history of hypertension and DM (Table 3).

\section{Logistic regression analysis between FEUA and baPWV or ABI}

To explore the predictive role of FEUA on high baPWV or low ABI, further multiple logistic regression analysis was performed. When FEUA was modeled continuously, the prevalence of high baPWV $(\geqslant 1400 \mathrm{~cm} / \mathrm{s})$ and low ABI $(\leqslant 0.9)$ decreased with an increase in FEUA [odds ratio(OR) for high baPWV: 0.597, 95\% confidence interval(CI): 0.454, 0.786; OR for low ABI: $0.214,95 \% \mathrm{CI}: 0.099,0.462$ ]. After adjustment for age, sex, smoking habits, alcohol consumption, history of hypertension, and history of DM, the OR for low ABI was $0.181(0.083,0.399)$ but the prevalence of high baPWV was no longer related to FEUA. When adjusted for metabolic components including SBP, DBP, waist circumference, glucose, TC, TG, LDL-C, and HDL-C, the respective adjusted ORs for high baPWV and low ABI were 0.653(0.464, $0.920)$, and $0.180(0082,0.395)$. When FEUA was modelled in quartiles, the respective ORs for high baPWV from the first to the third quartiles of FEUA were 1.777(1.323, 2.387); $1.561(1.158,2.104)$; and 1.680 (1.250, 2.259), respectively. The ORs for high baPWV still held significance after adjusting for metabolic components or age, smoking habits, alcohol consumption, history of hypertension, and history of DM but lost significance after adjusting for gender. The prevalence of low ABI was greatly elevated with the decrement of FEUA [ORs for the first to third FEUA quartiles were 6.977(2.062, 23.610); 5.123(1.475, 17.790); and $2.685(0.709,10.171)$, respectively] where the first and second ORs were significant and still held significance after adjusting for multiple confounders (Table 4).

Fig. 1. The differences of baPWV, ABI, serum UA, FEUA by gender.

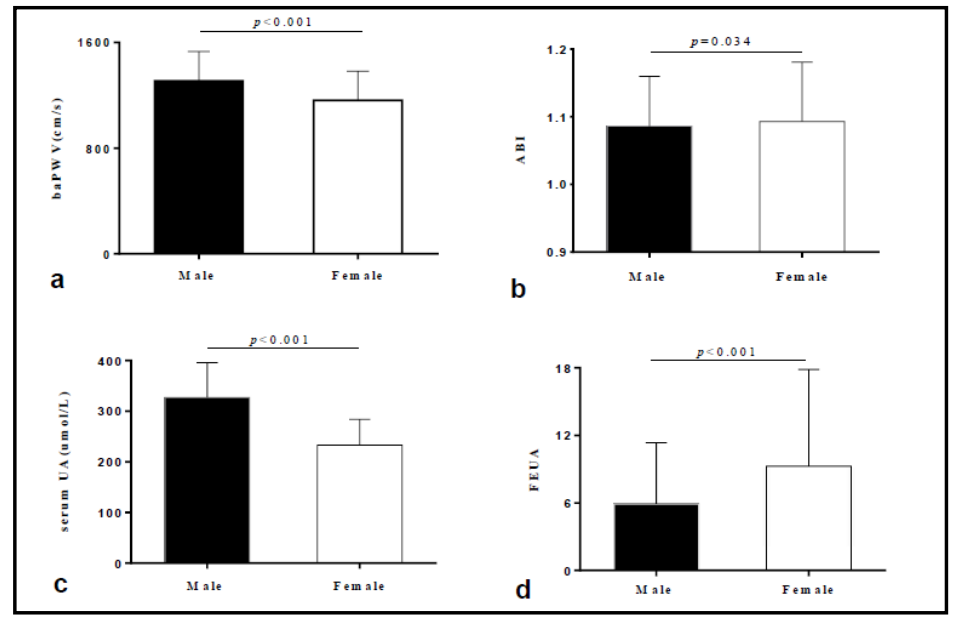

Table 3. Comparison of the correlations of serum UA or FEUA with baPWV or ABI. Abbreviations: UA=uric acid; FEUA= fractional excretion of uric acid; baPWV= brachial-ankle pulse wave velocity; $\mathrm{ABI}=$ ankle brachial index. Model1 unadjusted model. Model2 adjusted for age, smoke habits, alcohol consumption, history of hypertension, history of DM. Model3 based on model 2 and further adjusted for sex

\begin{tabular}{lccccc}
\hline Characteristics & & \multicolumn{4}{l}{ Correlation coefficients } \\
\hline Model & Index & baPWV & p values & ABI & p values \\
Model 1 & Serum UA & 0.338 & $<0.001$ & -0.117 & $<0.001$ \\
& FEUA & -0.100 & $<0.001$ & 0.229 & $<0.001$ \\
\multirow{3}{*}{ Model 2} & & & & & \\
& Serum UA & 0.268 & $<0.001$ & -0.014 & 0.511 \\
& FEUA & -0.55 & 0.007 & 0.033 & 0.110 \\
\multirow{2}{*}{ Model 3} & & & & & \\
& Serum UA & 0.166 & $<0.001$ & -0.009 & 0.674 \\
& FEUA & -0.004 & 0.829 & 0.032 & 0.127 \\
\hline
\end{tabular}




\section{Kidney Bloód Pressure Research}

Table 4. Logistic analysis between FEUA and baPWV or ABI. Abreviations: FEUA= fractional excretion of uric acid; baPWV= brachial-ankle pulse wave velocity; $\mathrm{ABI}=$ ankle brachial index. BaPWV and ABI were divided into two groups: baPWV $<1400 \mathrm{~cm} / \mathrm{s}$ or baPWV $\geqslant 1400 \mathrm{~cm} / \mathrm{s} ; \mathrm{ABI} \leqslant 0.9$ or $\mathrm{ABI}>0.9$. Model 1 unadjusted model. Model2 adjusted for age, smoke habits, alcohol consumption, history of hypertension, history of DM. Model3 based on model 2 and further adjusted for sex. Model4 adjusted for metabolic components including SBP, DBP, waist, glucose, TC, TG, LDL-C, HDL-C

\begin{tabular}{|c|c|c|c|c|c|}
\hline \multirow[t]{2}{*}{ Variables } & \multicolumn{4}{|c|}{ OR ( $95 \%$ confidence interval) } & \multirow{2}{*}{$\mathrm{p}$ values for trend } \\
\hline & Q1 & Q2 & Q3 & Q4 & \\
\hline \multicolumn{6}{|c|}{ High baPWV (baPWV $\geqslant 1400 \mathrm{~cm} / \mathrm{s}$ ) } \\
\hline Model 1 & $1.78(1.32,2.39)$ & $1.56(1.16,2.10)$ & $1.68(1.25,2.26)$ & 1(Reference) & $<0.001$ \\
\hline Model 2 & $1.37(1.00,1.88)$ & $1.34(0.98,1.84)$ & $1.47(1.07,2.01)$ & 1(Reference) & 0.002 \\
\hline Model 3 & $1.23(0.89,1.69)$ & $1.22(0.89,1.68)$ & $1.37(1.00,1.87)$ & 1(Reference) & 0.380 \\
\hline Model 4 & $1.53(1.07,2.20)$ & $1.50(1.04,2.15)$ & $1.62(1.13,2.33)$ & 1 (Reference) & 0.056 \\
\hline \multicolumn{6}{|c|}{ Low $A B I(A B I \leqslant 0.9)$} \\
\hline Model 1 & $6.98(2.06,23.61)$ & $5.12(1.48,17.79)$ & $2.69(0.71,10.17)$ & 1(Reference) & $<0.001$ \\
\hline Model 2 & $7.72(2.27,26.52)$ & $5.36(1.53,18.74)$ & $2.78(0.73,10.57)$ & 1(Reference) & $<0.001$ \\
\hline Model 3 & $8.56(2.48,29.60)$ & $5.78(1.65,20.26)$ & $3.00(0.79,11.44)$ & 1(Reference) & $<0.001$ \\
\hline Model 4 & $8.67(2.50,30.05)$ & $5.95(1.69,21.03)$ & $3.17(0.82,12.21)$ & 1 (Reference) & $<0.001$ \\
\hline
\end{tabular}

Fig. 2. Subgroup analysis of the relationship between FEUA and high baPWV or lowABI.

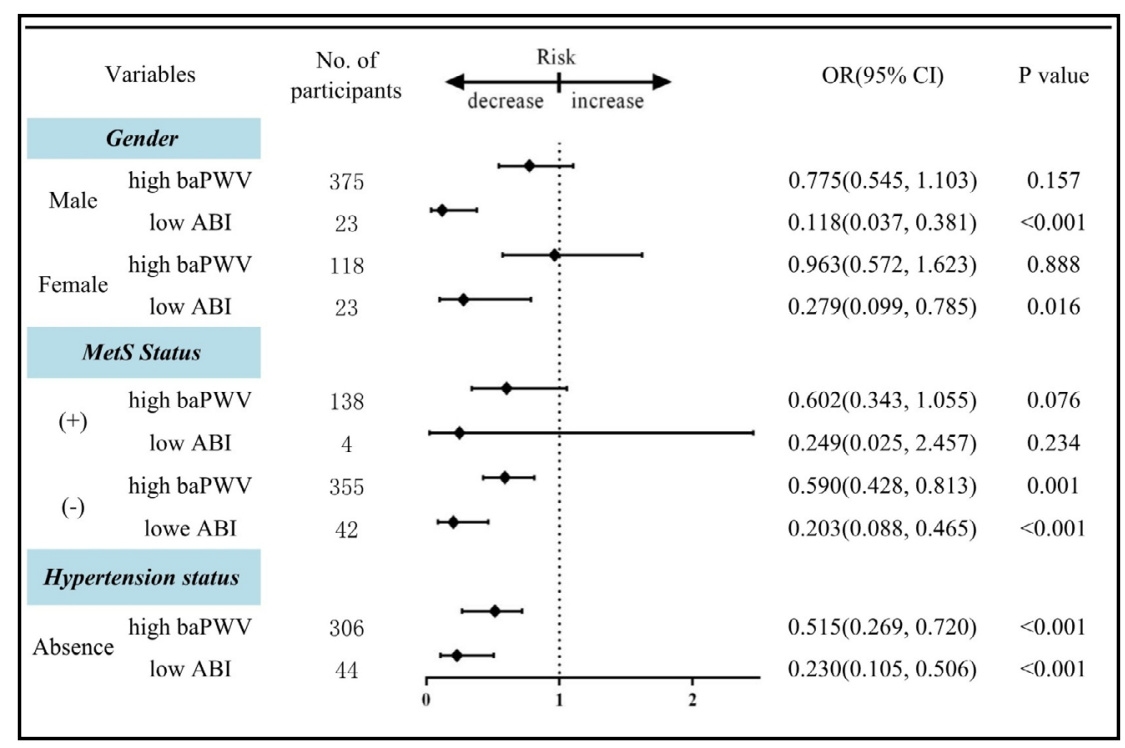

\section{Subgroup analysis}

Considering the profound effects of gender and MS on the excretion of UA, baPWV and $\mathrm{ABI}$, we conducted further analysis by dividing participants into two groups separately according to gender and MS to assess the influence of gender and MS on the interrelationship between UA and baPWV or ABI. As shown in Fig. 2, the risk of lower ABI decreased as FEUA increased which was independent of gender. This was attenuated but remained significant after adjusting for confounders. However, the relationship between FEUA and high baPWV was greatly influenced by sex and lost significance in both gender during disaggregated analysis. While subdivided according to MetS status, this relationship between FEUA and high baPWV or low ABI was significant in MetS (-) participants but lost significance in MetS (+). Additionally, higher FEUA predicted lower risk of abnormal baPWV or ABI after excluding hypertensive patients (Fig. 2). 


\section{Kidney Blood Pressure Research}

Fig. 3. The efficacies for FEUA and serum UA in the prediction of low ABI (a) and high baPWV (b).
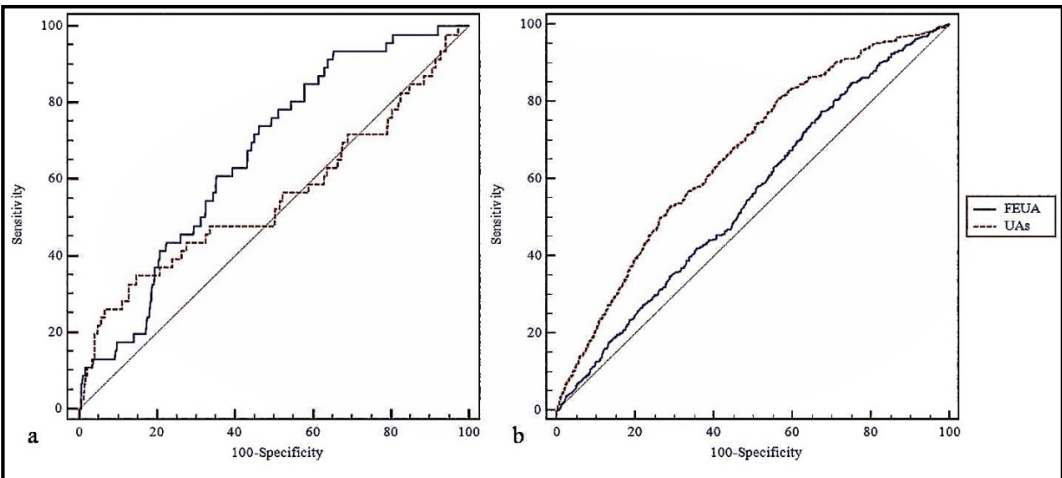

The differences between FEUA and serum UA

To compare the efficacies of FEUA and UA in the prediction of high baPWV or low ABI, we further analysed the correlations between UA and baPWV or ABI. As shown in Table 3, serum uric acid was significantly associated with baPWV $(r=0.338, p<0.001)$ and remained significant after adjusting for confounding factors. The weak but significant association of serum UA and ABI $(\mathrm{r}=-0.117, \mathrm{p}<0.001)$ became non-significant after corresponding confounding factor adjustment. In the prediction of the prevalence of high baPWV, serum UA was more effective than FEUA (areas of ROC curves: 0.662 vs $0.553, p<0.001$ ). Nevertheless, FEUA was more effective than serum UA in the prediction of lower ABI (areas of ROC curves: 0.664 vs $0.554, p=0.027$ ) (Fig. $3 \mathrm{a}, \mathrm{b}$ ).

\section{Discussion}

In the present study, we found that lower FEUA predicted a higher prevalence of high baPWV and low ABI. The association of FEUA and ABI was independent of related confounding factors. However, the association between FEUA and baPWV was greatly influenced by corresponding confounders, especially gender. The efficacy of FEUA in the prediction of low ABI was stronger than that of serum UA. However, serum UA was more powerful in the prediction of high baPWV. These results indicated that kidney function exerts an influence on the relationship between $\mathrm{UA}$ and baPWV and $\mathrm{ABI}$, revealing the complex interactions among cardiovascular risk factors.

The relationship between UA and baPWV or ABI has been discussed for years, but the results have been inconsistent. In this study, we firstly assessed the correlation of UA and baPWV or ABI using FEUA to determine the influence of renal function. The balance of UA was largely dependent on the kidneys, through which two-thirds of UA is excreted [19]. However, elevated UA was independently associated with the progression of renal damage, which indicated a vicious cycle between renal function and elevated UA[20, 21]. The multiethnic study of atherosclerosis indicated that lower arterial elasticity predicted faster kidney function decline in subjects with eGFR $>60 \mathrm{ml} /(\mathrm{min} \cdot 1.73 \mathrm{~m} 2)$. In addition, renal function also declined as ABI decreased [22]. These results revealed the intimate correlations of renal function with various cardiovascular risk factors. Through the influence of renal function, there are some indirect effects of UA on baPWV and ABI. Thus, renal function could modify the correlation between UA and baPWV or ABI. In this study, we found that the association of $\mathrm{UA}$ and baPWV or ABI was greatly influenced by kidney function. For the reason that the extents of influence of renal function on baPWV and $\mathrm{ABI}$ are quite divergent, the relationships of baPWV and ABI with serum UA or FEUA are different. Elevated UA could contribute to arteriolosclerosis of the renal afferent vessels and aggrevate inflammation, endothelial dysfunction of kidney, resulting in salt-sensitive hypertension [23]. UA may also influence 


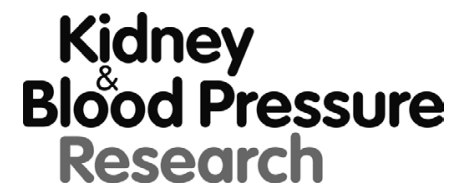

\begin{tabular}{l|l}
\hline Kidney Blood Press Res 2018;43:234-245 \\
\hline DOI: 10.1159/000487677 & $\begin{array}{l}\text { C } 2018 \text { The Author(s). Published by S. Karger AG, Basel } \\
\text { www.karger.com/kbr }\end{array}$ \\
\hline Published onlıne: February 27, 2018
\end{tabular}

Hu et al.: Correlations of FEUA with BaPWV and ABI

skin microvascular function [24]. These effects exposed people to a higher susceptibility to arterial stiffness. In addition, elevated UA and arterial stiffness also contributed to insulin resistance $[25,26]$. Insulin inhibited the excretion of UA and was inversely associated with FEUA. Thus, kidney could simultaneously influence the progression of arterial stiffness and UA elevation and may therefore enforce the relationship between UA and baPWV. Adjustment of renal function by using FEUA may mask some effects of the kidney. However, to a lesser extent, $\mathrm{ABI}$ was influenced by renal function. Oxidative stress was a major contributor of the pathogenesis of low ABI [27]. Though as a risk factor of CVD, UA could also act as an antioxidant and protect against oxidative damage [28]. Thus, accompanied with the decline of renal function, the detrimental effects and the antioxidative effect of UA are all enhanced. The enhancement of antioxidant effect may weaken the relationship between ABI and UA. Therefore, though the correlation of UA and baPWV or ABI still existed while using FEUA, baPWV was more intimately correlated with serum UA but the correlation with low ABI was stronger while using FEUA. In other words, renal function influences the strength of the correlation and the efficacy of assessment. The correlations of serum UA and other cardiovascular indices, to some extent, were also influenced by kidney function [29]. These results further strengthened the profound interaction of cardiovascular risk factors that synergetically promoted the progression of CVD.

Compelling studies revealed that the relationships between serum UA and arterial stiffness indices were different between genders, although their conclusions might not be consistent. Cristina et al. only found a positive link between serum UA and cfPWV in men [30]. But most studies supported that women were more vulnerable to the detrimental effects of UA. The morbidity and mortality of CVD or the decline of renal function attributed to elevated UA were all higher in female [31-33]. Gomez-Marcos et al. showed a positive result of the correlation between UA and cfPWV in women [29]. Asian studies also found a prominent correlation between UA and baPWV in female [34, 35]. A similar condition was found for the correlation of UA and ABI. A cross-sectional study among 6262 Chinese patients proposed that the association between UA and low ABI was stronger in women than in men and held significance after adjusting for eGFR only in women [12]. Given these facts, a gender-specific analysis was performed in the present study. The association between FEUA and low ABI was observed in men and women, with the association being stronger in women than in men. Our results were consistent with previous findings on this topic, which reported the effect size of UA and PAD association being stronger in women. Previous studies have found that women were exposed to a higher level of oxidative stress indicating by higher allantoin/UA ratio [36]. In addition, serum UA was more intimately associated with mean plalelet volume and insulin resistance in women [37]. These might synergetically contribute to a poor clinical outcome in females. Whether there are some sex-dependent pathogenesis pathways of UA is far from clear and further experimental researches are warranted.

Several studies have proposed that the associations of UA with cardiovascular risk factors were influenced by MetS status [38]. Two cross-sectional studies from Japan found that the prevalence of carotid atherosclerosis and carotid plaque increasing with elevated UA quartile was prominent in subjects without MetS $[39,40]$. A Chinese cohort also found that higher UA predicted higher prevalence of CVD in a MetS(-) group [41]. In line with those results, our study also found that the relationship between FEUA and baPWV or ABI was only significant in MetS (-) participants rather than MetS (+) participants. These might be attributed to the abnormal metabolism of UA in MS status. Under-excretion of UA partly contributed to high serum UA level in MS patients [9]. This fact further emphasized that kidney function modified the relationship of UA with other parameters. However, the generalization of this conclusion still needs further evidence for the limited number of individuals in the MetS(+) group in this study.

The mechanisms underlying the association of UA and baPWV or ABI are far from clear. Experimental studies found that elevated UA could promote the process of vascular inflammation by enhancing the expression of pro-inflammatory factors and oxidative stress 


\section{Kidney \\ Blood Pressure Research}

$[42,43]$. UA could also contribute to endothelial dysfunction and dysregulate the proliferation of vascular smooth muscle cells and endothelial cells [43]. Furthermore, animal models indicated that mild hyperuricemia contributed to renal afferent arteriolar fibrosis and media membrane thickening independent of BP [44]. However, temporary administration of UA in healthy men did not exert obvious effects on haemodynamics and endothelium-dependent vasodilation [45]. Future studies concentrating on the long-term effects of UA may shed light on better explanations.

There are some limitations that should be addressed. The study participants were all restricted in middle-aged Chinese and the range of age was quite small. Thus, the results of this study might not represent the whole population. Moreover, due to the cross-sectional nature of the present study, little causal inference or information regarding mechanisms could be drawn from the results. Longitudinal studies and basic research on the mechanisms are urgently needed to figure out the innate relationship between UA and baPWV or ABI. Furthermore, the interactions among various cardiovascular risk factors are full of complexity, thus residual confounders may still potentially account for our results, though many confounders have been adjusted.

\section{Conclusion}

Lower FEUA confers an increased risk of high baPWV and low ABI. The correlation between UA and baPWV or ABI was influenced by kidney function. These results revealed the complex interactions among cardiovascular risk factors and may provide further evidence for drug-selection and dietary intervention for relevant patients.

\section{Disclosure Statement}

The authors declare that there is no Disclosure Statement.

\section{Acknowledgements}

This work was supported by the National Natural Science Foundation of China No. 81370357, No. 81570381 (J.-J.M.), No. 81600327 (Y.W.) and No. 81700368 (C.C.), the Clinical Research Award of the First Affiliated Hospital of Xi'an Jiaotong University of China No. XJTU1AF-CRF-2015-006, Grant 2017YFC1307604 from the Major Chronic Noncommunicable Disease Prevention and Control Research Key Project of the Ministry of Science and Technology of the People's Republic of China, and Grant 2017ZDXM-SF-107 from the Key Research Project of Shaanxi Province.

\section{References}

1 Gagliardi AC, Miname MH, Santos RD: Uric acid: A marker of increased cardiovascular risk. Atherosclerosis 2009;202:11-17.

2 Lin Y, Lai X, Chen G, Xu Y, Huang B, Wu Y, Chen Z, Yao L, Lin F, Qiao Y, Chen Z, Zhu S, Huang H, Wen J: Association among serum uric acid, cardiovascular risk, and arterial stiffness: a cross-sectional study in She ethnic minority group of Fujian Province in China. J Endocrinol Invest 2012;35:290-297.

3 Bombelli M, Ronchi I, Volpe M, Facchetti R, Carugo S, Dell'oro R, Cuspidi C, Grassi G, Mancia G: Prognostic value of serum uric acid: new-onset in and out-of-office hypertension and long-term mortality. J Hypertens 2014;32:1237-1244. 


\section{Kidney \\ Blood Pressure Research}

Hu et al.: Correlations of FEUA with BaPWV and ABI

4 Feig DI, Soletsky B, Johnson RJ: Effect of allopurinol on blood pressure of adolescents with newly diagnosed essential hypertension: a randomized trial. JAMA 2008;300:924-932.

-5 Nakagawa T, Hu H, Zharikov S, Tuttle KR, Short RA, Glushakova O, Ouyang X, Feig DI, Block ER, HerreraAcosta J, Patel JM, Johnson RJ: A causal role for uric acid in fructose-induced metabolic syndrome. Am J Physiol Renal Physiol 2006;290:F625-F631.

6 Del BOH, Sedler MJ, Mera RM, Lama J, Gruen JA, Phelan KJ, Cusick EH, Zambrano M, Brown DL: The association of ankle-brachial index with silent cerebral small vessel disease: results of the Atahualpa Project. Int J Stroke 2015;10:589-593.

$>7$ Gronewold J, Hermann DM, Lehmann N, Kröger K, Lauterbach K, Berger K, Weimar C, Kälsch HI, Moebus S, Jöckel KH, Bauer M, Erbel R; Heinz Nixdorf Recall Study Investigative Group: Ankle-brachial index predicts stroke in the general population in addition to classical risk factors. Atherosclerosis 2014;233:545-550.

8 Wang Y, Mou Q, Zhao D, Xu Y, Hu D, Ma H, Liu J, Guo X, Li J: Predictive value of ankle-brachial index and blood glucose on the outcomes of six-year all-cause mortality and cardiovascular mortality in a Chinese population of type 2 diabetes patients. Int Angiol 2012;31:586-594.

-9 Wang Y, Xu Y, Hu D, Guo X, Zhao D, Li J: Joint association of ankle-brachial index and serum uric acid on the outcomes of six-year all-cause mortality and cardiovascular mortality in Chinese patients. Int J Cardiol 2012;158:144-145.

10 Ninomiya T, Kojima I, Doi Y, Fukuhara M, Hirakawa Y, Hata J, Kitazono T, Kiyohara Y: Brachial-ankle pulse wave velocity predicts the development of cardiovascular disease in a general Japanese population: the Hisayama Study. J Hypertens 2013;31:477-483.

11 Mehta T, Nuccio E, McFann K, Madero M, Sarnak MJ, Jalal D: Association of Uric Acid With Vascular Stiffness in the Framingham Heart Study. Am J Hypertens 2015;28:877-883.

12 Zhan Y, Dong Y, Tang Z, Zhang F, Hu D, Yu J: Serum Uric Acid, Gender, and Low Ankle Brachial Index in Adults With High Cardiovascular Risk. Angiology 2015;66:687-691.

13 Shin JY, Lee HR, Shim JY: Significance of high-normal serum uric acid level as a risk factor for arterial stiffness in healthy Korean men. Vasc Med 2012;17:37-43.

14 Perez-Ruiz F, Aniel-Quiroga MA, Herrero-Beites AM, Chinchilla SP, Erauskin GG, Merriman T: Renal clearance of uric acid is linked to insulin resistance and lower excretion of sodium in gout patients. Rheumatol Int 2015;35:1519-1524.

-15 Lee SK, Lanaspa MA, Sánchez-Lozada LG, Johnson RJ: Hyponatremia with Persistent Elevated Urinary Fractional Uric Acid Excretion: Evidence for Proximal Tubular Injury. Kidney Blood Press Res 2016;41:535544.

16 Tomiyama H, Matsumoto C, Shiina K, Yamashina A: Brachial-Ankle PWV: Current Status and Future Directions as a Useful Marker in the Management of Cardiovascular Disease and/or Cardiovascular Risk Factors. J Atheroscler Thromb 2016;23:128-146.

17 Wang Y, Mu JJ, Geng LK, Wang D, Ren KY, Guo TS, Chu C, Xie BQ, Liu FQ, Yuan ZY: Effect of salt intake and potassium supplementation on brachial-ankle pulse wave velocity in Chinese subjects: an interventional study. Braz J Med Biol Res 2015;48:83-90.

18 Alberti KG, Eckel RH, Grundy SM, Zimmet PZ, Cleeman JI, Donato KA, Fruchart JC, James WP, Loria CM, Smith SC Jr, International Diabetes Federation Task Force on Epidemiology and Prevention, Hational Heart, Lung, and Blood Institute, American Heart Association, World Heart Federation, International Atherosclerosis Society, International Association for the Study of Obesity: Harmonizing the metabolic syndrome: a joint interim statement of the International Diabetes Federation Task Force on Epidemiology and Prevention; National Heart, Lung, and Blood Institute; American Heart Association; World Heart Federation; International Atherosclerosis Society; and International Association for the Study of Obesity. Circulation 2009;120:1640-1645.

19 Maiuolo J, Oppedisano F, Gratteri S, Muscoli C, Mollace V: Regulation of uric acid metabolism and excretion. Int J Cardiol 2016;213:8-14.

20 Lytvyn Y, Škrtić M, Yang GK, Yip PM, Perkins BA, Cherney DZ: Glycosuria-mediated urinary uric acid excretion in patients with uncomplicated type 1 diabetes mellitus. Am J Physiol Renal Physiol 2015;308:F77-F83. 


\section{Kidney \\ Blood Pressure Research}

Kidney Blood Press Res 2018;43:234-245

\begin{tabular}{l|l}
\hline DOI: 10.1159/000487677 & (C) 2018 The Author(s). Published by S. Karger AG, Basel
\end{tabular}

Published onlıne: February 27, 2018

www.karger.com/kb

Hu et al:: Correlations of FEUA with BaPWV and ABI

21 Suzuki K, Konta T, Kudo K, Sato H, Ikeda A, Ichikawa K, Ueno Y, Kato T, Kayama T, Kubota I: The association between serum uric acid and renal damage in a community-based population: the Takahata study. Clin Exp Nephrol 2013;17:541-548.

22 Yan BP, Zhang Y, Kong AP, Luk AO, Ozaki R, Yeung R, Tong PC, Chan WB, Tsang CC, Lau KP, Cheung Y, Wolthers T, Lyubomirsky G, So WY, Ma RC, Chow FC, Chan JC; Hong Kong JADE Study Group: Borderline ankle-brachial index is associated with increased prevalence of micro- and macrovascular complications in type 2 diabetes: A cross-sectional analysis of 12, 772 patients from the Joint Asia Diabetes Evaluation Program. Diab Vasc Dis Res 2015;12:334-341.

-23 Johnson RJ, Rodriguez-Iturbe B, Nakagawa T, Kang DH, Feig DI, Herrera-Acosta J: Subtle renal injury is likely a common mechanism for salt-sensitive essential hypertension. Hypertension 2005;45:326-330.

-24 Wijnands JM, Houben AJ, Muris DM, Boonen A, Schram MT, Sep SJ, van der Kallen CJ, Henry RM, Dagnelie PC, van der Linden S, Schaper NC, Arts IC, Stehouwer CD: Uric acid and skin microvascular function: the Maastricht study. J Hypertens 2015;33:1651-1657.

-25 Hughes TM, Althouse AD, Niemczyk NA, Hawkins MS, Kuipers AL, Sutton-Tyrrell K: Effects of weight loss and insulin reduction on arterial stiffness in the SAVE trial. Cardiovasc Diabetol 2012;11:114.

-26 Muscelli E, Natali A, Bianchi S, Bigazzi R, Galvan AQ, Sironi AM, Frascerra S, Ciociaro D, Ferrannini E: Effect of insulin on renal sodium and uric acid handling in essential hypertension. Am J Hypertens 1996;9:746752.

27 Ebisawa S, Kashima Y, Miyashita Y, Yamazaki S, Abe N, Saigusa T, Miura T, Motoki H, Izawa A, Ikeda U: Impact of endovascular therapy on oxidative stress in patients with peripheral artery disease. Circ J 2014;78:1445-1450.

28 Fabbrini E, Serafini M, Colic BI, Hazen SL, Klein S: Effect of plasma uric acid on antioxidant capacity, oxidative stress, and insulin sensitivity in obese subjects. Diabetes 2014;63:976-981.

-29 Gómez-Marcos MA, Recio-Rodríguez JI, Patino-Alonso MC, Agudo-Conde C, Rodríguez-Sánchez E, GómezSánchez L, Gómez-Sánchez M, García-Ortiz L, Vasorisk group: Relationship between uric acid and vascular structure and function in hypertensive patients and sex-related differences. Am J Hypertens 2013;26:599607.

30 Baena CP, Lotufo PA, Mill JG, Cunha RS, Benseñor IJ: Serum Uric Acid and Pulse Wave Velocity Among Healthy Adults: Baseline Data From the Brazilian Longitudinal Study of Adult Health (ELSA-Brasil). Am J Hypertens 2015;28:966-970.

-31 Høieggen A, Alderman MH, Kjeldsen SE, Julius S, Devereux RB, De Faire U, Fyhrquist F, Ibsen H, Kristianson K, Lederballe-Pedersen O, Lindholm LH, Nieminen MS, Omvik P, Oparil S, Wedel H, Chen C, Dahlöf B; LIFE Study Group: The impact of serum uric acid on cardiovascular outcomes in the LIFE study. Kidney Int 2004;65:1041-1049.

-32 Heo SH, Lee SH: High levels of serum uric acid are associated with silent brain infarction. J Neurol Sci 2010;297:6-10.

-33 Obermayr RP, Temml C, Gutjahr G, Knechtelsdorfer M, Oberbauer R, Klauser-Braun R: Elevated uric acid increases the risk for kidney disease. J Am Soc Nephrol 2008;19:2407-2413.

-34 Ma W, Yang Y, Qi LT, Zhao F, Zhang BW, Meng L, Zhang Y, Jiang J, Li JP, Zhu SN, Wang SY, Huo Y: Association between serum uric acid and brachial ankle pulse wave velocity in Beijing community residents. Zhonghua Xin Xue Guan Bing Za Zhi 2012;40:204-208.

-35 Ishizaka N, Ishizaka Y, Toda E, Hashimoto H, Nagai R, Yamakado M: Higher serum uric acid is associated with increased arterial stiffness in Japanese individuals. Atherosclerosis 2007;192:131-137.

-36 Llull L, Laredo C, Renú A, Pérez B, Vila E, Obach V, Urra X, Planas A, Amaro S, Chamorro Á: Uric Acid Therapy Improves Clinical Outcome in Women With Acute Ischemic Stroke. Stroke 2015;46:2162-2167.

-37 Shimodaira M, Niwa T, Nakajima K, Kobayashi M, Hanyu N, Nakayama T: Gender differences in the relationship between serum uric acid and mean platelet volume in a Japanese general population. Platelets 2014;25:202-206.

-38 Fraile JM, Puig JG, Torres RJ, de Miguel E, Martínez P, Vázquez JJ: Uric acid metabolism in patients with primary gout and the metabolic syndrome. Nucleosides Nucleotides Nucleic Acids 2010;29:330-334.

-39 Takayama S, Kawamoto R, Kusunoki T, Abe M, Onji M: Uric acid is an independent risk factor for carotid atherosclerosis in a Japanese elderly population without metabolic syndrome. Cardiovasc Diabetol 2012;11:2. 


\section{Kidney \\ Blood Pressure Research}

40 Ishizaka N, Ishizaka Y, Toda E, Nagai R, Yamakado M: Association between serum uric acid, metabolic syndrome, and carotid atherosclerosis in Japanese individuals. Arterioscler Thromb Vasc Biol 2005;25:1038-1044.

41 Qin L, Yang Z, Gu H, Lu S, Shi Q, Xing Y, Li X, Li R, Ning G, Su Q: Association between serum uric acid levels and cardiovascular disease in middle-aged and elderly Chinese individuals. BMC Cardiovasc Disord 2014;14:26.

-42 Kanellis J, Watanabe S, Li JH, Kang DH, Li P, Nakagawa T, Wamsley A, Sheikh-Hamad D, Lan HY, Feng L, Johnson RJ: Uric acid stimulates monocyte chemoattractant protein-1 production in vascular smooth muscle cells via mitogen-activated protein kinase and cyclooxygenase-2. Hypertension 2003;41:12871293.

43 Kanellis J, Kang DH: Uric acid as a mediator of endothelial dysfunction, inflammation, and vascular disease. Semin Nephrol 2005;25:39-42.

44 Mazzali M, Kanellis J, Han L, Feng L, Xia YY, Chen Q Kang DH, Gordon KL, Watanabe S, Nakagawa T, Lan HY, Johnson RJ: Hyperuricemia induces a primary renal arteriolopathy in rats by a blood pressure-independent mechanism. Am J Physiol Renal Physiol 2002;282:F991-F997.

45 Waring WS, Adwani SH, Breukels O, Webb DJ, Maxwell SR: Hyperuricaemia does not impair cardiovascular function in healthy adults. Heart 2004;90:155-159. 